\title{
ETHICAL ASPECTS ABOUT INFORMED CONSENT IN CORD BLOOD COLLECTION FOR DIAGNOSTIC PURPOSES
}

\author{
Elena Tataranu ${ }^{1,2}$, Maria Stamatin ${ }^{1,2}$, Smaranda Diaconescu ${ }^{1,3}$, \\ Angelica Cristina Marin ${ }^{1}$, Cornelia Savescu ${ }^{1,3}$, Marin Burlea ${ }^{1,3}$ \\ 1 "Gr. T. Popa" University of Medicine and Pharmacy, Iasi, Romania \\ ${ }^{2}$ Mother and Child Department of "Gr. T. Popa" University of Medicine and \\ Pharmacy, Iasi, Romania \\ 3 “Sf. Maria” Emergency Clinical Hospital for Children, Iasi, Romania
}

\begin{abstract}
Deepening the knowledge about genetic and epigenetic mechanisms studies (environmental caused) regarding atopy, brought revelations about intrauterine onset of allergies, proven by the presence of IgE in umbilical cord blood.

Detection of these newborns and their inclusion in a specific care program further reduces the morbidity of allergic march with the undeniable effects on quality of life and healthcare costs.

The dramatic increase in the prevalence of atopy in recent decades suggests the importance of IgE in umbilical cord determinations. The use of umbilical cord blood for diagnostic purposes requires clear laws and rules and this is the subject we suggest to debate in this paper.
\end{abstract}

Keywords: informed consent, cord blood, atopy, IgE

\section{INTRODUCTION}

Recent epidemiologic data suggests a sudden dramatic increase of atopic syndromes in the late decades. Predisposition to hyper sensibility starts alongside immune development during the embryo-fetal period, atopic diseases often being diagnosed during the early years of life.

After the recurrent releases of these facts, the growing worldwide interest in primary prevention of atopic disorders is only the next logical step while early detection of high-risk groups during the perinatal period has become an essential tool for prevention and providing a better treatment strategy.

Many studies are currently trying to evaluate the impact maternal age, sex of the neonate, number of previous pregnancies, mode and season of delivery, past medical history, past drug history, family history of allergy and allergic diseases prior to preg- nancy can have on the presence and type of an allergic disease.

The primary feature that distinguishes atopic from non-atopic individuals is their predisposition for developing antigen-specific IgE antibodies when regularly exposed to foreign proteins in frequent low doses (pollen, house dust or food)(Koning et al.1996). The tendency to produce $\operatorname{IgE}$ is genetically determined (Marsh DG, Meyer SDA, Bias WB 1981, 1551-9) and/or secondary to intrauterine sensitization $(1,2)$.

Cord blood is one of the current propositions for use in diagnosing atopic infants given the impact of increased cord blood IgE levels upon the potential development of an allergic disease.

The leading aim of the current debate is to provide a theoretical analysis and critique of informed consent, particularly in the context of cord blood collection for research, diagnosis or therapy. Be- 
cause cord blood is often assessed for its therapeutic potential prior to research or intended donation, the issues around collection consent for therapy and research overlap tremendously.

\section{Scientific background regarding cord blood}

Cord blood is defined as the residual placental blood collected from the cord of the newborn.

In 1924, the sociologist Marcel Mauss, a major contributor to the analysis of meaning of the notion "gift", published the book Essai sur le Don: Forme et Raison de l'Échange dans les Sociétés Archaiques, in which he analyzed in depth the concepts of donating, receiving and returning (3). His follower Alain Caillé, in Critique de la Raison Utilitariste and in L'Esprit du Don stated that these free gestures are decisive in societal evolvement (4).

Laboratory experiments have demonstrated that cord blood stem cells can differentiate into various cell types, thus giving rise to future potential new diagnostic and therapeutic uses.

Studies performed on twins suggest that the antigenic specificity of cord blood is strongly influenced by environmental factors (5) while this alternative is considered by some authors to be unlikely because the $\operatorname{IgE}$ antibodies appear to be the result of spontaneous nonspecific IgE production, probably because of suppression, rather than exogenous antigenic stimulation.

\section{Legal background regarding the use of cord blood}

Most European countries have no specific legislation regarding cord blood collection and/or banking, preferring to follow different practices; only a few, including Italy, enacting specific rules on the issue. When regulations for human tissue or human blood exist at large (ex: France) then cord blood is considered a tissue and not blood because the hematopoietic progenitor cells that it contains are important for transplantation (6).

The Directive of the European Parliament and the Council on setting standards of quality and safety for donations, procurement, testing, processing, preservation, storage and distribution of human tissues and cells, adopted on $2^{\text {nd }}$ March 2004, covers hematopoietic progenitor cells but excludes blood and other blood products.

The European Health Committee of the Council of Europe has also made a draft Recommendation on autologous blood banks, an opinion though, not yet adopted by the Committee of Ministers. In this recommendation the following are stated (7):

1. "If cord blood banks are established, they shall be from altruistic and voluntary cord blood donation and used for allogeneic transplantation and related research.

2. The promotion of donation for autologous use and the establishment of cord blood banks for autologous use should not be supported by member States or their health services.

3. Accurate information should be provided to the population about the advantages and disadvantages of cord blood banking.

4. Where autologous cord blood banks are being established, the publicity and information provided to families must be accurate and fully informed consent to cord blood storage must be obtained.

5. Autologous blood banks that are being established must meet the same quality and safety standards as set out in the Council of Europe's Guide to safety and quality assurance for organs, tissues and cells."

Since 1999 Romania has a representative in the Transplant Committee of the Council of Europe (Prof. Dr. Irinel Popescu), and adopted the European stipulations regarding transplantation, a fact that led to the promulgation in 2006 of a new Romanian transplantation law adapted to European requirements. In 1998 the first modern law for transplantation was issued in Romania - Law no. 2/1998 "regarding the prelevation and transplantation of human tissues and organs", in which all the conditions for harvesting and transplanting organs and tissues were specified. This law was replaced by Title VI "Performing prelevation and transplantation of organs, tissues and cells of human origin with therapeutical purposes" of Law 95/2006 "regarding the reform in the field of health", in which a detailed chapter regarding transplantation of cells and tissues also exists, while the regulations regarding organ transplantation are updated.

\section{Ethical background regarding the use of cord blood}

There are several fundamental ethical principles and values that can be considered relevant for cord blood collection:

- The principle of respect for human dignity and integrity, which asserts the principle of non commercialization of the human body;

- The principle of autonomy or the right to self-determination on the basis of full and correct information;

- The principles of justice and solidarity, as regards to fair access to healthcare services;

- The principle of beneficence, or the obligation to do good, especially in the area of health care; 
- The principle of non-maleficence, or the obligation not to harm, including the obligation to protect vulnerable groups and individuals, to respect privacy and confidentiality;

- The principle of proportionality, which implies a balance between means and objectives.

\section{Cord blood collection for diagnostic purposes}

Presumably, the levels of IgE in cord blood, together with a possible placental transfer of maternal IgE, are determined primarily by a fetal intrauterine immune reaction to allergens and other factors (such as smoking) with a base background represented by genetic determinants. Several findings support the role of IgE levels in the cord blood as a marker for prediction of atopic syndromes $(1,2,8)$ : the fetus can produce IgE starting from the $11^{\text {th }}$ week of gestation (9), maternal IgE does not cross the placental barrier (10), and the presence of a correlation between high IgE levels in newborns and tendency to develop an atopic disease during infancy or adulthood (11). Other markers found in the cord blood that have been evaluated as predictors of allergy are the number of eosinophils, the decline of suppressor $\mathrm{T}$ cells, the increase of $\mathrm{TH} 2$ lymphocytes, certain phenotypes $\alpha$-1-antitrypsin, specific IgG anti- $\beta$-lactoglobulin, IL4 and interferon gamma levels as they are involved in $\mathrm{IgE}$ regulation.

\section{Informed consent in cord blood collection}

Consent in the context of cord blood collection presents many of the same considerations as consent to other forms of tissue donation, and more broadly, consent in other contexts for research and/ or therapy. It is thus useful to understand the historical context in which the formal practices of obtaining consent and their associated justifications have emerged, both legally and ethically, and in particular its justification as rooted in the autonomy ideal.

The principle of respect for autonomy emerged during the last quarter of the twentieth century as the primary justification for informed consent practices in clinical medicine and biomedical research (12). The "triumph of autonomy" in bioethics is described as a stark contrast to the paternalism that previously prevailed in medical and research practice, and generally, the Hippocratic tradition $(13,14)$. The idea of informed consent evolved during an era shaped by many social factors and upheavals. Researchers who work with human sub- jects often do so with the goal of attaining knowledge that contributes to human health and well-being. In this process it is arguably necessary to ensure that considerations of the greater good of society are not attained at the price of sacrificing the personal autonomy of individuals if viewed as subjects.

In most cases there are three potential parties whose consent should be considered: the newborn, the mother and the father. Biologically, very nearly all the components of the umbilical cord and its contents are genetically those of the infant, not the mother. Nevertheless the cord blood may also contain some of the mother's cells as well. Therefore, the provision of informed consent for the collection and storage of cord blood from the newborn is complicated by the fact that a baby clearly cannot be a self-directing voluntary participant. To that extent the baby is an involuntary donor of blood and/ or tissue, with the mother often acting as proxy for informed consent.

The timing of soliciting informed consent has remained a controversial issue in clinical practice (15). Two distinctions are important in this regard: the first one, between informed consent for cord blood collection and cord blood storage/use, and the second one between in-utero and ex-utero collection. General consensus upholds the requirement that informed consent for collection, storage, and use of cord blood should be obtained prior to labour and delivery (15).

Professional organizations in the United States, Canada and the UK support the position that the consent of the mother should be considered necessary and sufficient for cord blood donation; this is also the standard practice of national cord blood programs in those countries $(16,17)$. A strong case can be made in support of this position. First, many collections take place in vivo during the third stage of labour while the placenta has yet to be delivered. It may be considered as an "extension" of the woman's body and collection of the cord blood thus considered a procedure on the mother (18). Second, even for ex vivo collections, the cord blood may be considered a product of the mother's labour in childbirth.

Netcord-FACT, the world's most widely acknowledged accrediting body for cellular-based therapies, provides greater flexibility in the timing of consent for cord blood collection, allowing for initial consent for collection any time prior to delivery (after an explanation of the basic purpose, benefits, risks, and services to be performed) and full written consent to be obtained at a later time. 
Therefore in cases where full consent cannot be obtained during the prenatal period, these guidelines seem to allow for women to be approached for consent to cord blood collection during labour; once cord blood is collected and tested (that is, if testing shows the collected cord blood unit to be clinically viable), women are to be approached in the postpartum period (usually within 48 hours, due to quality control requirements) to consider consent to continued storage and use of the cord blood.

In our opinion, aspects of ownership and property rights are notoriously fraught and form part of an extensive jurisprudential corpus.

We believe that in case of diagnostic purposes, parents should be informed that the cord blood is to be used in order to determine the levels of various biochemical and cellular indicators and that they will be notified if an illness is identified, clarifying that the collected sample will be used for research and therapeutic purposes with no personal benefit for the medical care provider. The parents are to be informed that no neonatal blood is retained force- fully in the placenta and no alteration occurs secondary to early ligation.

\section{CONCLUSIONS}

The cord blood IgE level is thought to be a predictor of allergic disorders in childhood. It is not well understood how maternal and paternal characteristics, placenta, fetal attributes and environment, influence this marker thus making cord blood collection compulsory. There is worldwide a lack regarding the informed consent in cord blood collection for diagnostic reasons, especially, in IgE level in maternal and child blood as strong predictors for atopic sensitivity. In theory, informed consent is intended to achieve a justifiable and desirable goal of respect for the individuals. Informed consent practices originally evolved as a response to abuses of human subjects in research, and as a way of negating charges of assault and battery in clinical practice.

10. Bazaral M., Orgel H.A., Hamburger R.N. IgE levels in normal infants and mothers and an inheritance hypothesis. J Immunol 1971; 107(3):794-801.

11. Kjellman N.I.M., Johansson S.G. IgE and atopic allergy in newborns and infants with a family history of atopic disease. Acta Paediatr Scand 1976; 65(5):601-7.

12. Beauchamp T.L., Childress J.F. Principles of Biomedical Ethics. $5^{\text {th }}$ ed. New York: Oxford University Press; 2001.

13. Wolpe P.R. The triumph of autonomy in American bioethics: A sociological view. In: DeVries $\mathrm{R}$ and Subedi J, editors. Bioethics and Society: Constructing the Ethical Enterprise. New Jersey: PrenticeHall; 1998. p. 38-59.

14. Veatch R.M. The Basics of Bioethics. $2^{\text {nd }}$ ed. New Jersey: Prentice Hall; 2003.

15. Kurtzberg J., Drapkin Lyerly A., Sugarman J. Untying the Gordian knot: policies, practices and ethical issues related to banking of umbilical cord blood. J Clin Invest 2005; 115(10):2592-2597.

16. American Academy of Pediatrics. Cord blood banking for potential future transplantation: Subject review. Pediatrics 2005; 140(1):116118.

17. Armson B.A., Maternal/Fetal Medicine Committee. Umbilical cord blood banking: Implication for perinatal care providers. J Obstet Gynaecol Can 2005; 27(3):263-274.

18. Plant M., Knoppers B.M. Umbilical cord blood banking in Canada: Socio-ethical and legal issues. Health Law J 2005; 13:187-212.

9. Miller D.L., Hirvonen T., Gitlin D. Synthesis of $\mathrm{lgE}$ by the human conceptus. J Allergy Clin Immunol 1973; 52(3):182-188. 